\title{
FACESHEET DELAMINATION OF COMPOSITE SANDWICH MATERIALS AT CRYOGENIC TEMPERATURES
}

\author{
Thomas S. Gates*, Gregory M. Odegard†, Helen M. Herringł \\ NASA Langley Research Center, Hampton VA 23681 \\ ${ }^{*}$ Mechanics and Durability Branch, †National Institute of Aerospace, ¥Lockheed Martin
}

\begin{abstract}
The next generation of space transportation vehicles will require advances in lightweight structural materials and related design concepts to meet the increased demands on performance. One potential source for significant structural weight reduction is the replacement of traditional metallic cryogenic fuel tanks with new designs for polymeric matrix composite tanks. These new tank designs may take the form of thin-walled sandwich constructed with lightweight core and composite facesheets. Life-time durability requirements imply the materials must safely carry pressure loads, external structural loads, resist leakage and operate over an extremely wide temperature range. Aside from catastrophic events like tank wall penetration, one of the most likely scenarios for failure of a tank wall of sandwich construction is the permeation of cryogenic fluid into the sandwich core and the subsequent delamination of the sandwich facesheet due to the build-up of excessive internal pressure.

The research presented in this paper was undertaken to help understand this specific problem of core to facesheet delamination in cryogenic environments and relate this data to basic mechanical properties. The experimental results presented herein provide data on the strain energy release rate (toughness) of the interface between the facesheet and the core of a composite sandwich subjected to simulated internal pressure. A unique test apparatus and associated test methods are described and the results are presented to highlight the effects of cryogenic temperature on the measured material properties.
\end{abstract}

\section{INTRODUCTION}

Future space transportation vehicles will require lightweight structures and materials to meet the increased demands on performance. One area identified as a potential source for significant weight reduction is the replacement of metallic cryogenic fuel tanks with polymeric matrix composite (PMC) tanks. A promising structural concept based on PMC materials is to use a sandwich construction with the $\mathrm{PMC}$ as the facesheet material and lightweight polymeric materials as the core. As outlined extensively by Gibson and Ashby [1], the sandwich construction technique has many advantages over typical stiffened skin concepts, not the least of which is reduced weight. However, sandwich construction has a number of potential problems because the presence of multiple interfaces serves as a source for failure initiation and growth.

The interest in design of cryogenic-fuel tanks for spacecraft using polymeric composite materials goes back several years to the research associated with the National Aerospace Plane (NASP) and the singlestage-to-orbit (SSTO) vehicles [2]. Concepts were proposed for both the liquid-oxygen tanks and the liquid-hydrogen tanks. These studies addressed weight and cost benefits as well as the complex technical issues such as fatigue crack resistance and oxidation-corrosion resistance. It was recognized that permeation resistance of the tanks could be the overriding design criteria because of the implications that damage and the resulting permeation or leak would have on both durability and safety of the vehicle.

One of the first demonstrations of a PMC cryogenic fuel tank occurred in 1996 when the DC-XA suborbital demonstration vehicle was built with an all-composite liquid-hydrogen fuel tank [3]. The DC-XA tank was designed as an unlined and unstiffened cylinder measuring approximately $2.4 \mathrm{~m}$ in diameter. The tank performed as expected in both ground and flight tests. 
It was recognized that the unstiffened shell design would not work for larger tanks and therefore the design of the large tanks would require some means to provide global and local stiffening. To avoid the potential weight penalties associated with a stiffened shell design, sandwich construction was considered. For an integrated cryogenic tank (i.e. one that is integral to the airframe structure), the tank wall must carry structural and pressure loads while operating over an extremely wide temperature range. One possible failure mechanism, associated with the use of sandwich materials in such a demanding environment, is debonding of the facesheet. This mechanism can occur due to high pressure inside the core material and is facilitated by the occurrence of cryopumping. Cryopumping can occur in closed cells during repeated cryogenic fluid fill and drain cycles and is simply the condensation of a gas on a cryogenically cooled surface that results in a vacuum or greatly decreased pressure inside the cells [4]. For a cryotank with PMC sandwich materials in the tank walls, this cryopumping will occur when the tank wall facesheet(s) develop leaks and allow the cryogen to permeate into the core. Subsequent warming of the cryogen causes a transition from a liquid to a gas phase and results in a substantial increase in core pressure. Without proper venting of this pressure, the core, facesheet, and bondline must sustain the resultant pressure loads without failure [5]. The most likely initial failure mode due to cryopumping is facesheet-tocore debonding that can lead to crack growth and a total separation of the facesheet.

Most notably, this failure mode occurred in the NASA X-33 reusable flight demonstration vehicle. The $\mathrm{X}$-33 was designed with a large $(8.7 \times 6.1 \times 4.3$ meter $)$, conformal tank made from a sandwich construction of polymeric composite skins and phenolic core. After successful completion of the first protoflight pressure and loads test, the tank was drained of its liquid hydrogen fuel, and a purge of the tank began. Approximately 15 minutes after the tank was drained, the outer facesheet and core separated from the inner facesheet along part of the tank wall [6]. It was subsequently determined that many factors contributed to the tank failure. Considering the mechanics of the failure, it was found that the inner tank wall allowed permeation (and hence cryopumping) by way of microcracks in the facesheet. As pressure and strain decreased below that required to sustain the microcrack paths, the leak paths closed. As the tank warmed, the remaining trapped cryogens proceeded to vaporize, creating high pressure. This pressure, coupled with bondline defects, likely caused the failure. The failure or debonding location occurred almost exclusively at the core-to-adhesive surface on the inner facesheet side.

The objective of this paper is to provide results on the combined experimental and analytical investigation of the facesheet-to-core debonding failure mode in PMC sandwich materials at cryogenic temperatures. The paper provides details on the material, test fixtures, test specimen design, test methods, model development, and fracture analysis. The experimental studies were performed at room temperature, $-196^{\circ} \mathrm{C}$, and $-269^{\circ} \mathrm{C}$ to provide basic material properties and critical fracture parameters associated with failure. To obtain the fracture parameters, a novel test method was designed to simulate the failure mode associated with facesheet debonding in the presence of pressure in the sandwich core.

\section{MATERIAL AND TEST SPECIMENS}

The test specimen was a sandwich construction made from a complex arrangement of composite facesheets, adhesive, and honeycomb core materials and is shown schematically in Fig. 1. The test method was based on a three-point bend approach relying on the sandwich beam to react the bending load.

\section{MATERIALS}

The PMC facesheet material used in this study was IM7/977-2 and the laminates consisted of a 15-ply quasi-orthotropic laminate ([45/90/-45/0/-45/90/45/0/45/90/-45/0/-45/90/45]) fabricated with a per-ply thickness of $.132 \mathrm{~mm}$. The fundamental lamina properties are given in table 1 as a function of temperature where the standard laminated plate notation is used such that 1-fiber direction, 2-transverse direction, 12-shear. The core material was Kevlar 6.0pcf, 3/16" (non-perforated), the adhesive was EA9696AL, and the permeability barrier was 5056-H39 (3.5 mil) aluminum foil. All test materials were fabricated at the Northrop Grumman Corporation.

For reference purposes, the sandwich longitudinal direction was defined as the direction parallel to the core ribbon direction and the transverse direction was defined as the direction perpendicular to the ribbon direction (Fig. 1). The core material was manufactured in a regular hexagonal pattern and the average area of the core hexagon was estimated to be $24.2 \mathrm{~mm}^{2}$. The inner facesheet was defined as the laminate to be debonded during tests and the outer facesheet was defined as the opposite laminate. 
Using the definitions provided by [1], the relative density of the core is calculated from

$$
\rho^{*} / \rho_{s}=\frac{(t / l)(h / l+2)}{2 \cos \theta(h / l+\sin \theta)}
$$

where $\rho^{*}$ and $\rho_{s}$ are the honeycomb-core density and density of core base material, respectively. The following dimensions describe the core geometry

$$
\theta=30^{\circ}, h=3.86 \mathrm{~mm}, l=2.67 \mathrm{~mm}, t=0.15 \mathrm{~mm}
$$

where $\theta=$ wall angle, $h=$ cell height, $l=$ cell length, and $t=$ wall thickness. Using these values and equation 1 , the relative core density was 0.057 . Defining the coordinate directions for the core to be $(1,2,3)$ where $(1,2)$ are in the plane of the hexagon (Fig. 1) and (3) is out of the plane, and using the superscript * and the subscript $s$ to define the honeycomb and base material, respectively, expressions for directional modulus $(E)$ are found from [1].

$$
\frac{E_{1}^{*}}{E_{s}}=\frac{E_{2}^{*}}{E_{s}}=2.3(t / l)^{3} \ll 1
$$

Equation (2) implies a very low relative stiffness of the core for in-plane loading. For out-of-plane loading, [1] provides the formula to estimate the relative, out-of-plane stiffness, that is,

$$
\frac{E_{3}^{*}}{E_{s}}=\frac{\rho^{*}}{\rho_{s}}=.057
$$

\begin{tabular}{|c|c|c|c|}
\hline & $\mathbf{2 3}^{\circ} \mathbf{C}$ & $-196^{\circ} \mathbf{C}$ & $\mathbf{- 2 6 9}^{\circ} \mathbf{C}$ \\
\hline $\mathbf{E}_{1}(\mathbf{G P a})$ & 180.2 & 134.6 & 158.6 \\
\hline $\mathbf{E}_{2}(\mathbf{G P a})$ & 8.3 & 11.4 & 11.6 \\
\hline $\mathbf{G}_{12}(\mathbf{G P a})$ & 6.2 & 7.2 & 7.8 \\
\hline$\alpha_{11}\left(\mu \varepsilon /{ }^{\circ} \mathbf{C}\right)$ & -.5 & -1.0 & NA \\
\hline$\alpha_{22}\left(\mu \varepsilon /{ }^{\circ} \mathbf{C}\right)$ & 30.0 & 15.5 & NA \\
\hline
\end{tabular}

Table 1. Measured material properties of PMC facesheets at each test temperature. The symbols E, G, $\alpha$ represent Young's modulus, shear modulus, and coefficient of thermal expansion respectively. (NA=not available)

\section{FRACTURE TEST SPECIMENS}

Fracture tests were conducted on rectangular specimens of the sandwich material. As shown in Fig. 2 , the tests specimens were cut into a beam shape with the overall dimensions of $152 \times 25.4 \times 31.2 \mathrm{~mm}$. The intent of the fracture tests was to debond the inner facesheet by growing a crack along the core/adhesive/facesheet interface region. Figures 3 and 4 illustrate the position of the specimen relative to the test fixture. To provide space for the center load bar, each test specimen had a $25.4 \mathrm{~mm}$ diameter through-hole cut in the specimen adjacent to the inner facesheet at the midpoint of the beam's length. To facilitate the growth of the crack, a starter crack was cut across the width on each side of the hole with a thin saw blade to approximately one cell depth along the facesheet-to-core interface. 


\section{PUSH-OFF TEST FIXTURE}

As illustrated in Fig. 3 and the photograph of Fig. 4, a unique test fixture was developed [7] to perform the facesheet push-off fracture tests. The basic concept for this test was to use a three-point bend apparatus that loaded the facesheet from inside the sandwich beam and grew a crack along the interface region of the core, adhesive, and facesheet. The applied load was reacted at the ends of the beam by circular rods acting as simple supports. A stiff base plate supported the whole apparatus. For the cryogenic tests, the apparatus was placed in an aluminum vessel that was filled with liquid cryogen prior to the start of the test run. As shown in the schematic of Fig. 3, the apparatus and test specimen remained submerged in the cryogenic fluid during the course of the test run.

\section{FRACTURE ANLAYSIS}

The influence of temperature on the strain-energy release rate for laminated composite materials has been examined in recent studies. In one study [8], the tests were performed on an epoxy based composite material using the double cantilever beam (DCB) specimen. It was found that the value of strain-energy release rate (SERR), $G$ (Mode I), increased approximately two-fold when the test temperature was lowered from room temperature to $-196^{\circ} \mathrm{C}$. In a similar study, [9] found the value of $G$ (Mode I, DCB specimen) for the material IM7/977-3 decreased when the temperature was lowered from room temperature to $-196^{\circ} \mathrm{C}$ by a factor of approximately 1.5 . These somewhat conflicting studies indicate that additional work may be required to standardize toughness tests at cryogenic temperatures for laminated materials.

For the sandwich material, a delamination forming near the skin-core interface in sandwich constructions can be of two types, interface and sub-interface. Interface cracks grow between the skin and core and sub-interface cracks form when an initial interface crack kinks into the core and then propagates parallel to the skin within the core. The type of delamination considered by the current work is limited to the interface type.

The analysis method outlined here is based on the compliance calibration method, or Berry's method, as given by [10] and [11]. Additional information on this method and other types of Mode I fracture tests can be found in reference [12].

\section{COMPLIANCE}

The calculated compliance of the test specimen was based on the load and displacement measurements during test. The compliance is given by,

$$
C=\frac{P}{\delta}
$$

where $C$ is compliance, $P$ is load and $\delta$ is the fixture displacement at the point of load application. Specimen compliance was then related to crack length through an empirical relationship,

$$
C=b a^{m}
$$

where $a$ is the crack length, and $b$ and $m$ are empirical constants determined through a linear fit to a double logarithmic plot of $C$ versus $a$.

\section{STRAIN ENERGY RELEASE RATE}

In general, the critical SERR is a function of the strain energy and crack length

$$
G_{c}=\frac{d U}{d a}
$$

where $G_{c}$ is the critical SERR and $U$ is the strain energy. For a specimen of width $w$, Eq. (6) gives

$$
G_{c}=\frac{P \delta}{2 w C} \frac{d C}{d a}
$$

and then using Eqs. (4) and (5), the critical SERR rate becomes 


$$
G_{c}=\frac{P^{2}}{2 w}\left(m b a^{(m-1)}\right)
$$

From this last equation, the critical SERR is calculated by using the four experimentally determined parameters: $m, b, a$, and $P$.

\section{TEST PLAN}

The test plan was constructed to investigate the fracture toughness as a function of temperature. The three test temperatures investigated were room temperature $\left(23^{\circ} \mathrm{C}\right)$ and two cryogenic temperatures (liquid $\mathrm{N}_{2}$ at $-196^{\circ} \mathrm{C}$ and liquid $\mathrm{He}$ at $-253^{\circ} \mathrm{C}$ ). The specimen orientation investigated was longitudinal where the orientations were defined previously. At least 3 replicates for each test condition were used to develop the final data.

\section{EXPERIMENTAL METHODS AND PROCEDURES}

The use of the novel test presented herein required development of new experimental methods and data-reduction procedures. The test methods fall into one of two broad categories; facesheet push-off and debond crack measurement.

\section{PUSH-OFF TEST}

The push-off test was run in a servo-hydraulic test machine using displacement control at a rate of $0.0254 \mathrm{~mm}$ per second. Load, as measured by the test machine load cell, and displacement, as measured by the test machine transducer, were monitored and recorded as a function of test time at a sampling frequency of $0.25 \mathrm{~Hz}$.

By adjusting the starting position of the actuator, the initial applied load for each test was kept at zero. A typical test run had several distinct sections or events that are illustrated in the typical load-versusdisplacement data of Fig. 5. During the loading phase of a test, the load-versus-displacement curve was approximately linear until the crack started to grow.

Due to the nature of the crack growth in the honeycomb/facesheet interface, the major portion of crack growth would occur with a significant and fast reduction in load. At this point in the test, the test operator would initiate a controlled reversal in displacement that would result in unloading of the test specimen.

The unloading phase had two distinct portions that were distinguished by an abrupt change in the slope of the load-versus-displacement curve. This abrupt change is also illustrated in Fig. 5. The compliance, as given by Eq. (4), was determined from this final unloading portion of the curve. The effective crack length, calculated using the procedures described below, was then plotted as a function of compliance on a double logarithmic scale and fit with Eq. (5) as illustrated by the example data presented in Fig. 6.

In general, the crack growth associated with such a test run would be small but measurable and would represent some fraction of the total specimen length. In order to quantify the crack length as a function of load and displacement, this typical test run would then be repeated 3 to 5 times or until the crack approached to within approximately $25 \mathrm{~mm}$ of the reaction rollers. Load versus displacement data for a typical series of test runs is given in Fig. 7.

\section{CRACK MEASUREMENT VIA X-RAY INSPECTION}

The crack, which developed during the course of loading, was quantified by calculating an effective crack length based on the number of debonded cells. To quantify this debond, the specimen was removed from the test fixture after each run and examined by an $\mathrm{x}$-ray radiography method. Briefly, this method consisted of injecting a small amount of dye penetrate into the crack on both sides of the center hole and then subjecting the specimen to a focused x-ray in the through-the-thickness direction. As shown by the typical x-ray images in Fig. 8, the debonded cells appeared as dark regions on the image and were easily distinguishable. As illustrated in Fig. 8, the center section of each specimen was where the cut-out was made to accommodate the load bar. 
With an accurate count of debonded cells established, an effective crack length was then calculated using

$$
\bar{a}=\frac{A_{c} n_{D B}}{w}
$$

where $\bar{a}$ is the effective crack length, $A_{c}$ is the area of a single cell (given previously), $n_{D B}$ is the number of debonded cells counted in the x-ray image, and $w$ is the specimen width. It should be noted that the cells in the center cut-out area and those cells debonded by the starter crack were also counted as debonded cells and used in calculating $n_{D B}$.

After completion of all the test runs, the inner facesheet was completely separated from the remaining bonded core and the failure surface was examined visually.

\section{RESULTS}

The primary variable considered in this study was test temperature. The effect of this variable on stiffness, strain-energy release rate, crack growth, and the fracture surface will be considered herein.

\section{STIFFNESS}

Review of the data in Table 1 clearly indicates that the stiffness of the laminated facesheet can be a function of both ply orientation and temperature. Orientation was the biggest factor with a difference in stiffness between longitudinal and transverse directions on the order of $60 \%$. Both facesheets exhibited an increase in stiffness with a decrease in temperature.

In comparison to many commercial systems [1] that can have relative densities in the range of 0.2 to 0.3, the relative density (Eq. (1)) of the core was quite low. Correspondingly, the in-plane and out-of-plane stiffness, as given by Eq.s (2) and (3), respectively, were also low, compared to many commercial systems.

\section{STRAIN ENERGY RELEASE RATE}

The critical SERR $G_{c}$ (Eq. (8)) was found for all test temperatures. In order to characterize the critical SERR, mean values were computed by using all the data over the entire range of effective crack length. Table 2 provides the computed values of strain energy release rate for a given effective crack length.

The room temperature data indicates that there was no appreciable scatter between the replicate specimens. In general, $G_{c}$ tended to decrease as crack length increased. The lack of significant differences between $\mathrm{G}_{\mathrm{c}}$ for the $-196^{\circ} \mathrm{C}$ and $-269^{\circ} \mathrm{C}$ tests prompted the combination of these data sets into a single "cryogenic temperature" data set. As with the room temperature data, the cryogenic temperature data showed some decrease with increasing crack length. The mean value of the cryogenic $G_{c}$ is greater than the room temperature value and the degree of scatter increased as compared to the room temperature data. Data scatter was attributed to the increased difficulty in discerning distinct crack growth while enclosed in the cryogenic test chamber as compared to the ease of operation at room temperature. Both data sets were combined into one plot, Figure 9, to illustrate the overall toughness trend with temperature. The mean values of $G_{c}$, were computed to be $3.90\left(\mathrm{in}-\mathrm{lb} / \mathrm{in}^{2}\right)$ and $4.84\left(\mathrm{in}-\mathrm{lb} / \mathrm{in}^{2}\right)$ for the room temperature and cryogenic data, respectively, and it was determined that $G_{c}$ increased by approximately $20 \%$ with a decrease from room to cryogenic temperatures.

\section{CRACK GROWTH AND FRACTURE SURFACE}

The $x$-ray images for most specimens showed relatively stable crack growth as a function of the load. However, in some cases the crack front was not uniform and the debonded region was irregular. In all cases, Eq. (9) was used to calculate the effective crack length.

For all cases, regardless of test temperature, the post-test examination of the fracture surface showed that failure always occurred along the core-to-adhesive bond line. The core separated cleanly from the inner barrier film and the adhesive tended to remained bonded to the inner facesheet.

\section{SUMMARY AND CONCLUDING REMARKS}

The in-plane stiffness of the composite facesheets was a strong function of laminate orientation and a weak function of test temperature. In general, the stiffness of the facesheets increased with a decrease in 
temperature. Therefore, it is expected that the bending stiffness of the entire test specimen would be a function of facesheet orientation and exhibit an increase as test temperature decreases.

Examining the SERR results from the current study of sandwich material, it was determined that $G_{c}$ increased with a decrease in temperature. In general, the $G_{c}$ values decreased with an increase in crack length.

The test apparatus and associated experimental methods developed in this study provided a novel approach to measuring the toughness of the facesheet-to-core bond and simulating the loading due to internal, core pressure. The primary experimental difficulties associated with this test method were related to the measurement of crack length.

\begin{tabular}{|c|c|c|c|c|}
\hline \multicolumn{2}{|l|}{ Test Temperature $\mathbf{7 0}^{\circ} \mathbf{C}$} & & \multicolumn{2}{|c|}{ Test Temperature - Cryogenic } \\
\hline $\mathrm{a}(\mathrm{mm})$ & $\mathrm{G}_{\mathrm{C}}\left(\mathrm{J} / \mathrm{m}^{2}\right)$ & & $\mathrm{a}(\mathrm{mm})$ & $\mathrm{G}_{\mathrm{C}}\left(\mathrm{J} / \mathrm{m}^{2}\right)$ \\
\hline 55.1 & 664.4 & & 49.8 & 668.1 \\
\hline 63.6 & 611.1 & & 54.5 & 957.9 \\
\hline 71.2 & 528.8 & & 54.5 & 984.4 \\
\hline 87.4 & 481.8 & 47.8 & 796.4 \\
\hline 47.9 & 735.6 & 64.7 & 748.2 \\
\hline 61.1 & 763.6 & & 71.3 & 712.9 \\
\hline 71.4 & 671.4 & 94.7 & 7606.0 \\
\hline 79.9 & 597.4 & & 48.5 & 991.5 \\
\hline 94.0 & 594.0 & & 62.5 & 898.6 \\
\hline 54.9 & 772.9 & & 77.4 & 685.5 \\
\hline 65.3 & 743.1 & & 51.4 & 968.3 \\
\hline 77.6 & 663.2 & & 69.1 & 665.8 \\
\hline 84.2 & 618.8 & & 53.4 & 698.0 \\
\hline
\end{tabular}

Table 2. Effective crack length and corresponding strain energy release rate for both the room temperature and cryogenic tests.

\section{REFERENCES}

1. Gibson, L.J. and M.F. Ashby. Second ed, Cellular Solids, Structure and Properties. 1997, Cambridge: Cambridge University Press.

2. Robinson, M.J., Composite Cryogenic Propellant Tank Development in 35th Structures, Structural Dynamics, and Materials Conference, AIAA-94-1375-CP, April, 1994, Hilton Head, South Carolina, p.544551.

3. Robinson, M.J., Composite Structures on the DC-XA Reusable Launch Vehicle in 28th International SAMPE, November, 1996, Seattle, Washington.

4. Barron, R.F. Second ed, Cryogenic Systems. 1985, New York: Oxford University Press.

5. Robinson, M.J., J.D. Eichinger, and S.E. Johnson, Hydrogen Permeability Requirements and Testing for Reusable Launch Vehicle Tanks in 43rd AIAA/ASME/ASCE/AHS Structures, Structural Dynamics, and Material Conference, AIAA-2002-1418, 2002, Denver, Colorado.

6. NASA, Final Report of the X-33 Liquid Hydrogen Tank Test Investigation Team, George C. Marshall Space Flight Center, Huntsville, NASA Report, 2000, May

7. Gates, T.S. and H.M. Herring, Facesheet Push-off Tests to Determine Composite Sandwich Toughness at Cryogenic Temperatures in AIAA 42nd SDM Conference,, AIAA-2001-1219, 2001, Seattle, WA. 
8. Aoki, T., T. Ishikawa, H. Kumazawa, and Y. Morino, Mechanical Performance of CF/Polymer Composite Laminates Under Cryogenic Conditions in 41st Structures, Structural Dynamics, and Materials Conference, AIAA-2000-1605, April, 3, 2000: American Institute of Aeronautics and Astronautics, Atlanta, GA.

9. Donaldson, S.L. and R.Y. Kim, Interlaminar Fracture of Carbon Fiber Reinforced Epoxy and Bismaleimide Composites at Cryogenic Temperatures in American Society of Composites, 15th Technical Meeting, September 25, 2000: American Society of Composites, College Station, TX.

10. Berry, J.P., Determination of Fracture Energies by the Cleavage Technique, Journal of Applied Physics, 1963, 34(No. 1): p. 62-68.

11. Cantwell, W.F. and P. Davies, A test technique for assessing core-skin adhesion in composite sandwich structures, Journal of Material Science Letters, 1994, 13: p. 203-205.

12. O' Brien, T.K. and R.H. Martin, Round Robin Testing for Mode I Interlaminar Fracture Toughness of Composite Materials, Journal of Composites Technology \& Research, 1993, 15(4): p. 269-281. 


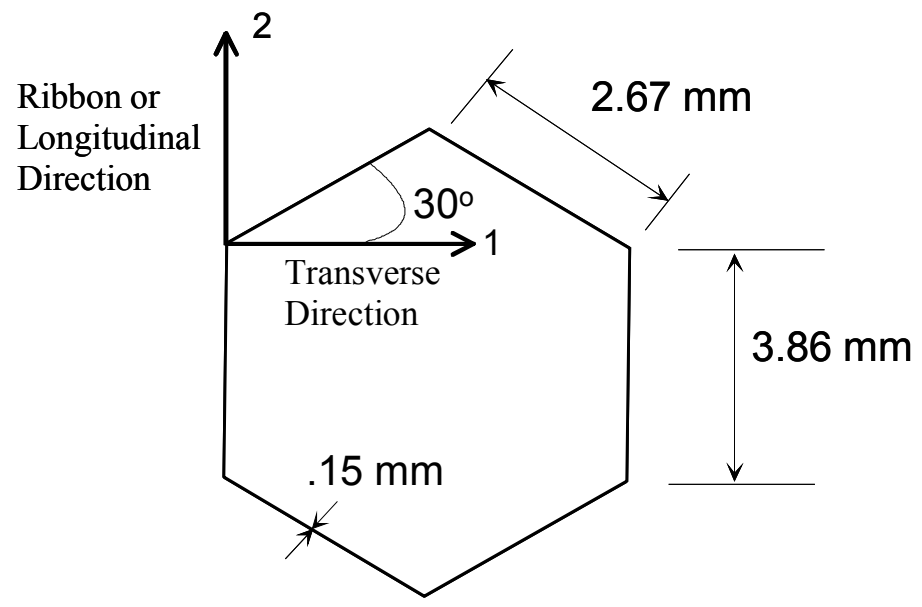

Figure 1. Schematic illustration of typical honeycomb cell geometry.
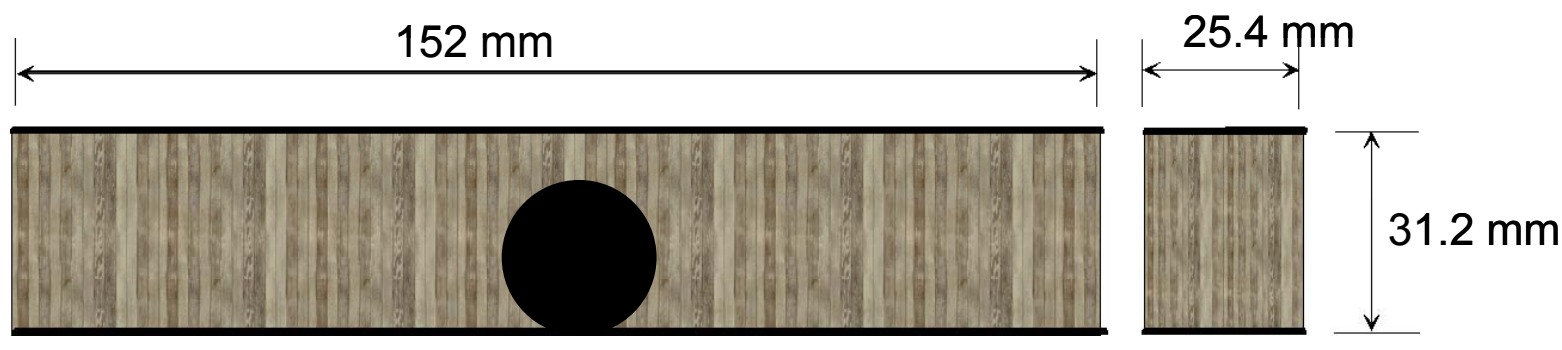

Figure 2. Schematic illustration of beam test specimen geometry.

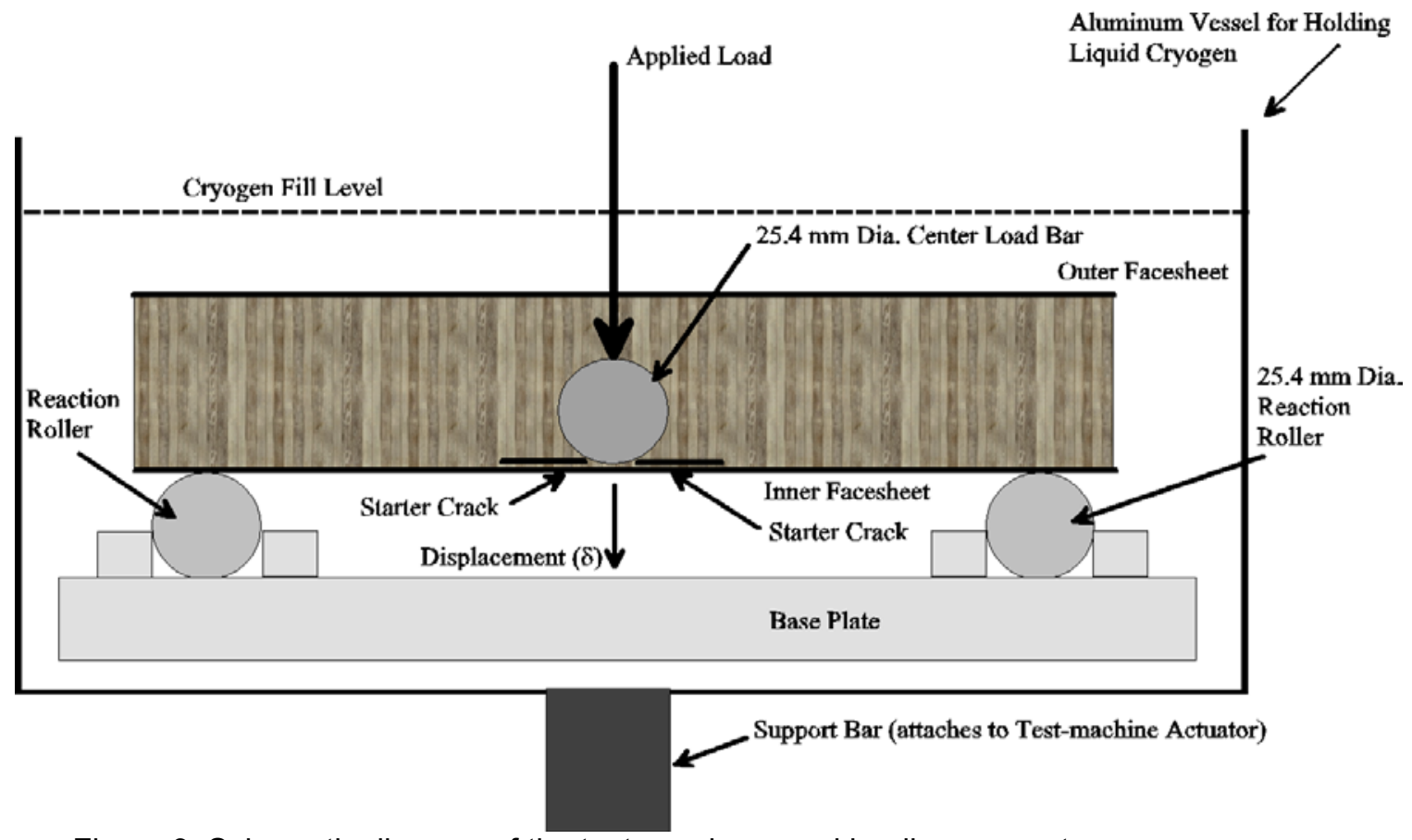

Figure 3. Schematic diagram of the test specimen and loading apparatus. 


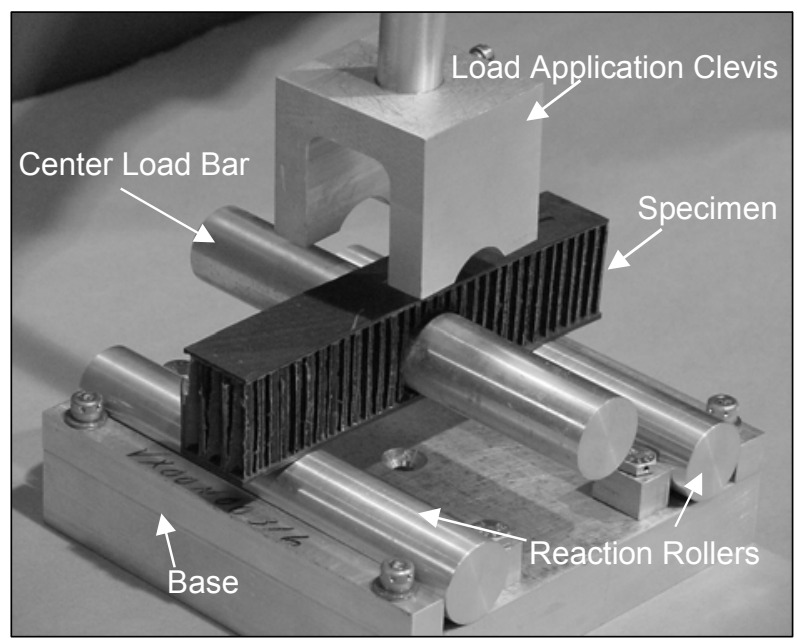

Figure 4. Photograph of the loading apparatus and typical test specimen.

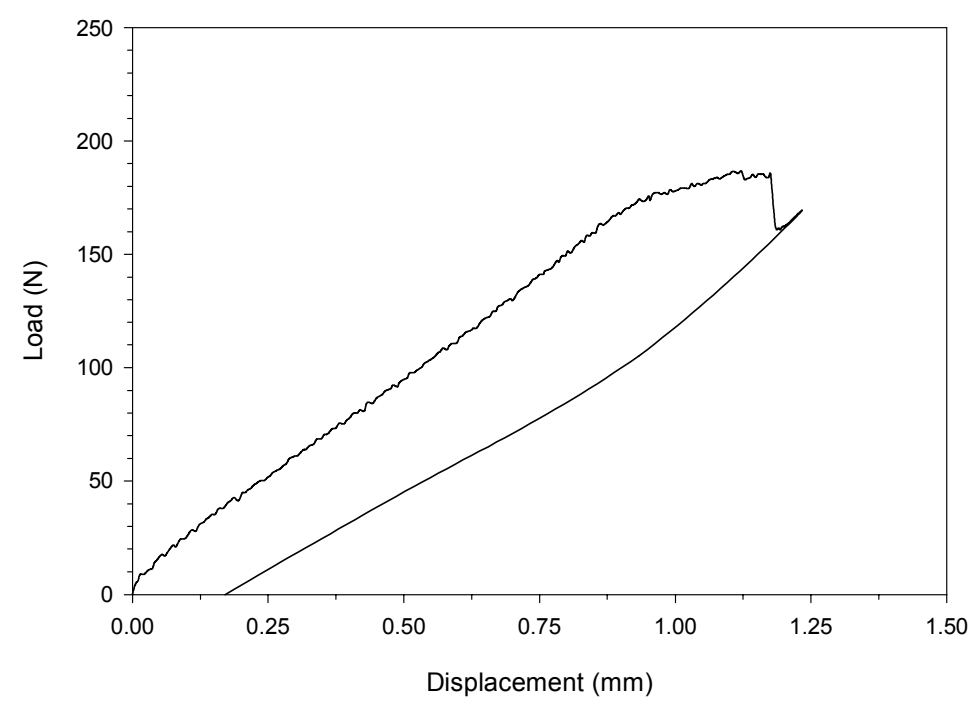

Figure 5. Typical load-displacement data for a single test run.

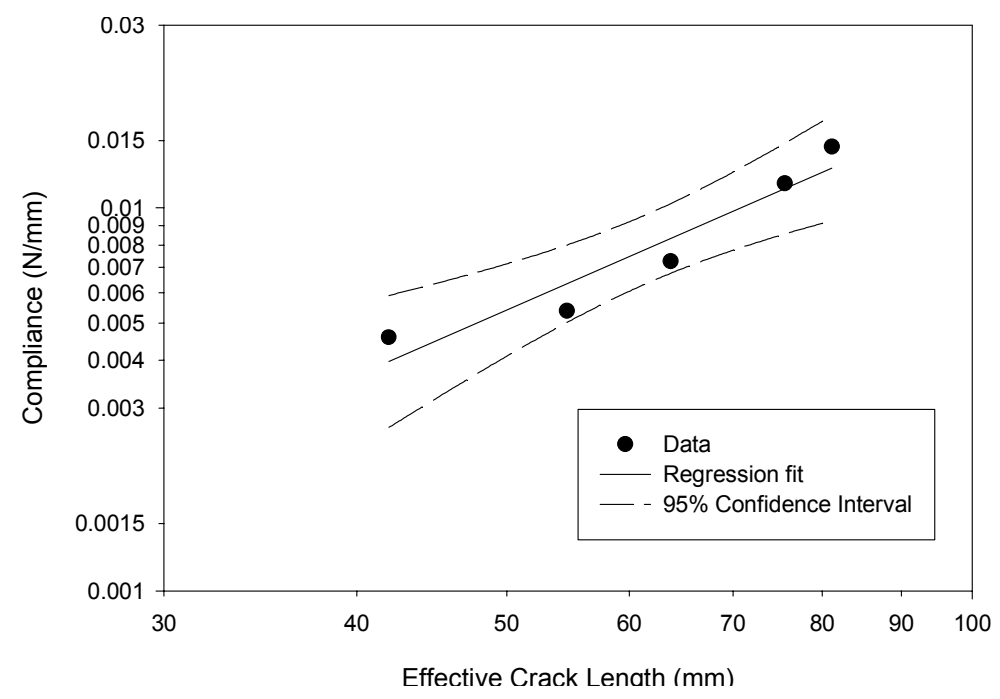

Figure 6. Typical compliance versus crack length data for a series of five test runs on a single specimen. 


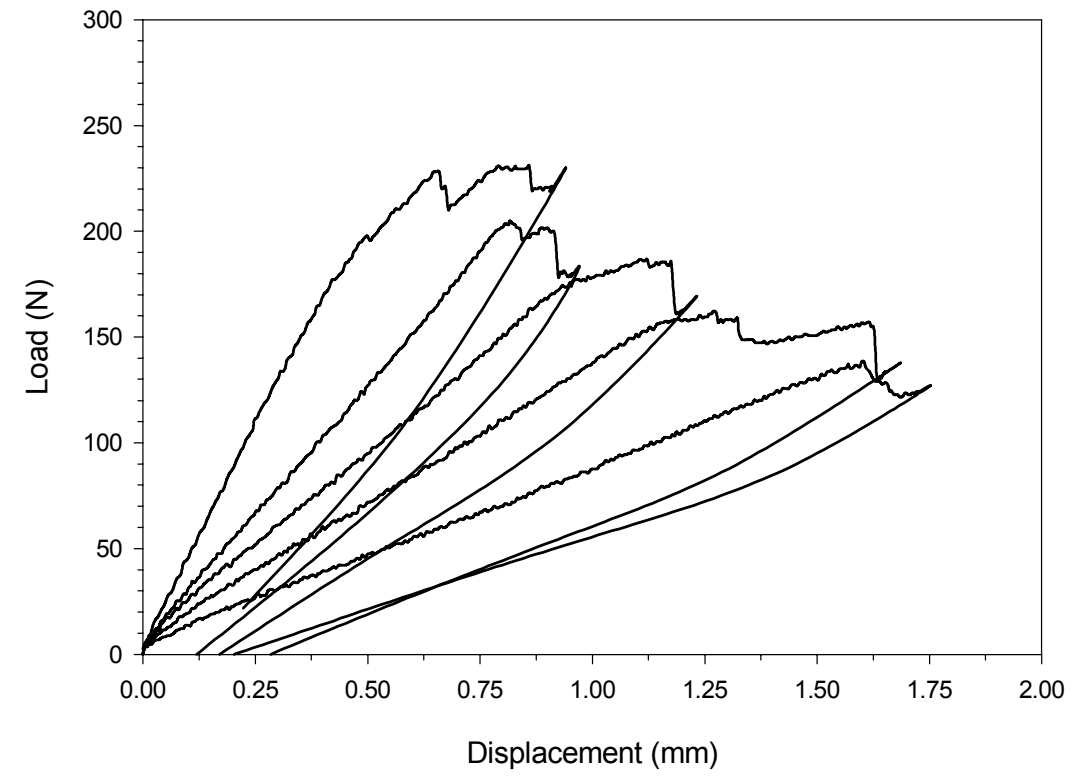

Figure 7. Typical load versus displacement data for five runs on a single test specimen.

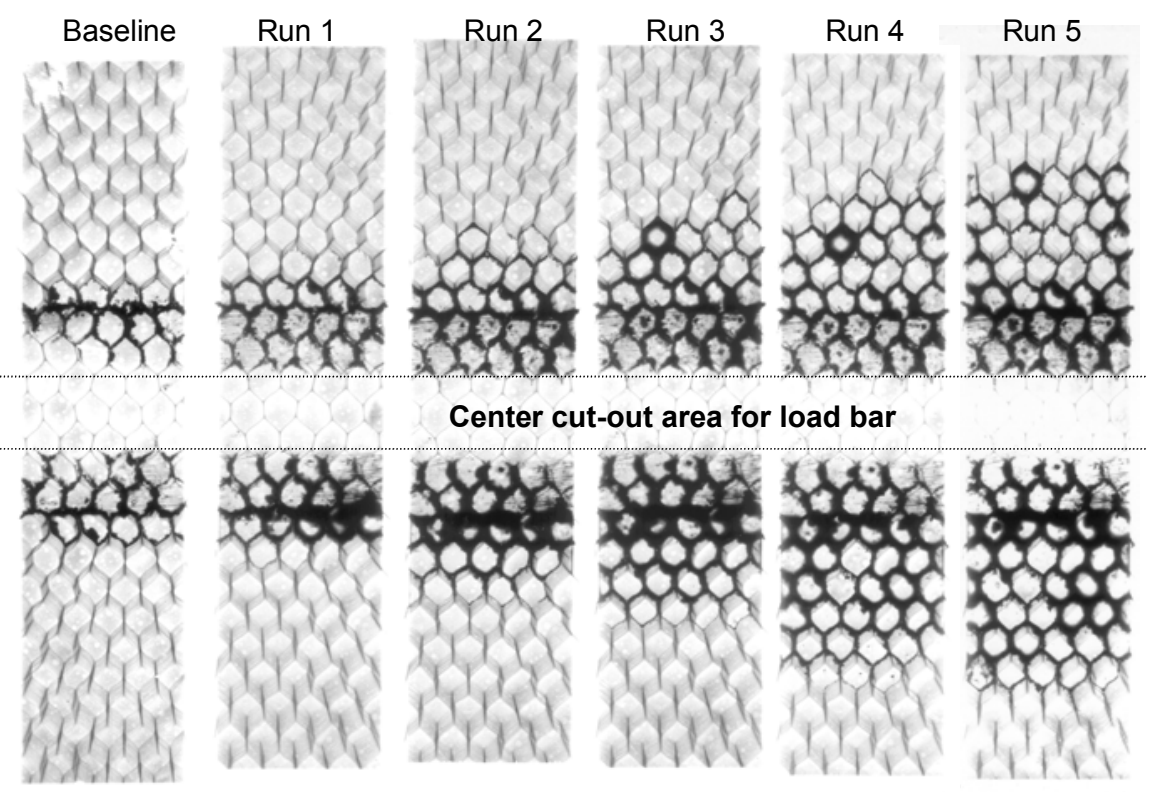

Figure 8. Typical x-ray images illustrating the extent of the crack or debonded cells for five consecutive runs on a single test specimen. 


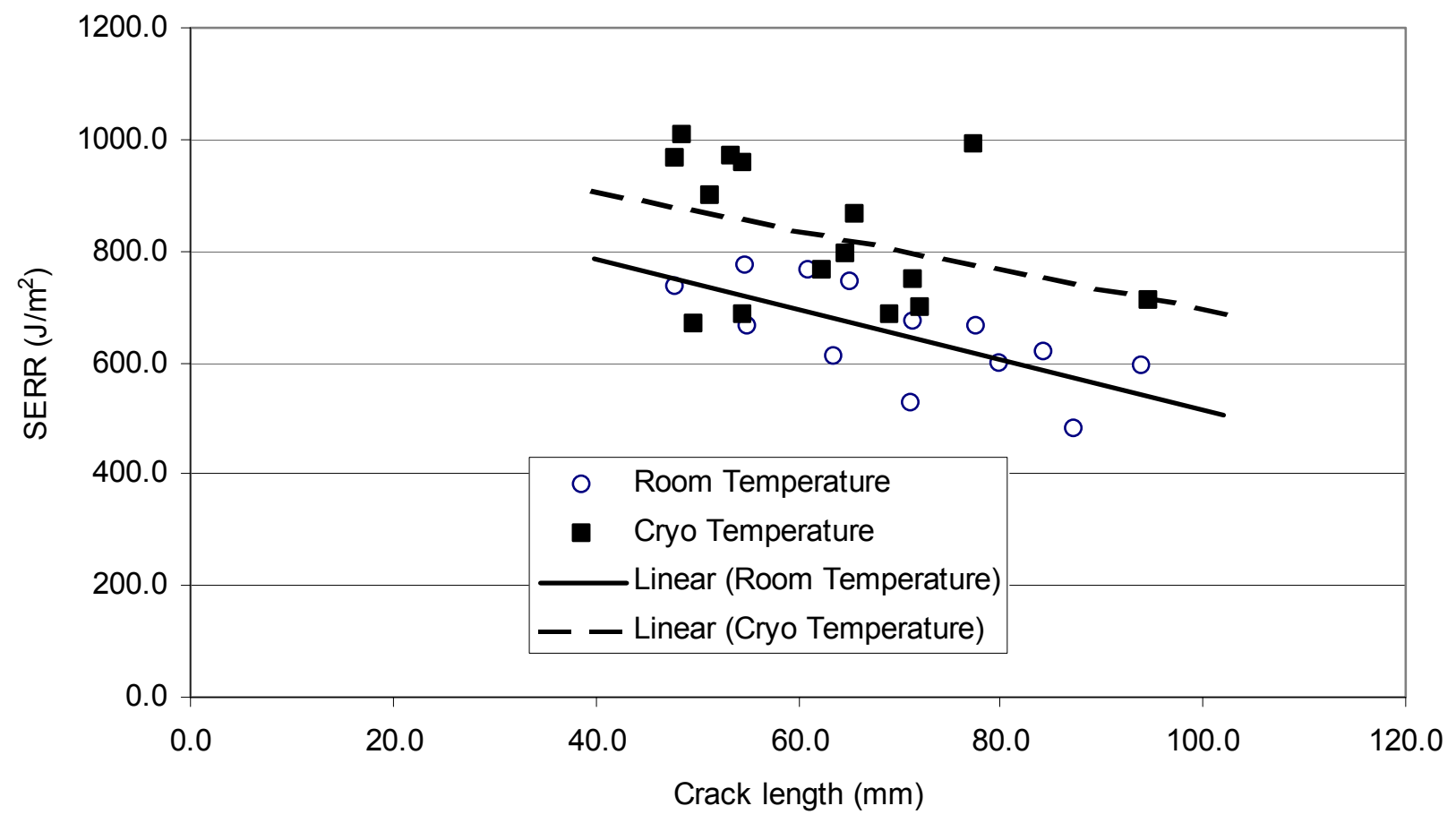

Figure 9. Strain energy release rate (SERR) versus crack length data as a function of temperature. Straight lines are linear regression fits to the respective data sets. 